\title{
EDUCAÇÃO COMO PROCESSO HUMANIZADOR E POLÍTICO NA UNIVERSIDADE PÚBLICA
}

\author{
EDUCACIÓN COMO PROCESO DE HUMANIZACIÓNY DE POLÍTICA EN LA \\ UNIVERSIDAD PÚBLICA
}

\author{
EDUCATION AS HUMANIZING PROCESS AND POLITICAL IN PUBLIC \\ UNIVERSITY
}

\author{
Maria José de PINHO $^{1}$ \\ John Devid Ribeiro SANTOS ${ }^{2}$
}

RESUMO: Este artigo tem como objetivo analisar a educação e sua função humanizadora na universidade pública no Brasil, bem como seu ato político, no qual há diferentes projetos em disputa na sociedade que se revelam nos diversos mecanismos e elementos que compõem o pensar e o fazer na docência no ensino superior. Trata-se de uma pesquisa teórica de cunho bibliográfico. Julgamos este assunto relevante para pensar os diferentes projetos para a universidade pública, no qual podem contribuir para promover a humanização ou reproduzir os mecanismos de dominação social. O estudo revelou que o desafio da universidade pública no Brasil é compreender a contradição social, econômica e política na universidade. E um dos horizontes está na autoformação do indivíduo enquanto sujeito envolvido no processo de estudo e aprendizagem, na busca incessante pelo conhecimento.

PALAVRAS-CHAVE: Educação. Humanização. Universidade pública.

RESUMEN: Este artículo tiene como objetivo analizar la educación y su papel en la humanización de la universidad pública en Brasil, así como su acto político, en el que hay diferentes proyectos en disputa en la sociedad que revelan los distintos mecanismos y elementos que conforman el pensamiento y hacer en la enseñanza en la educación superior. Esta es una investigación teórica de la naturaleza bibliográfica. Creemos que este asunto relevante para pensar acerca de los diferentes proyectos para la universidad pública, que pueden ayudar a promover la humanización o jugar los mecanismos de dominación social. El estudio reveló que el reto de la universidad pública en Brasil es entender la contradicción social, económica y política universitaria. Y uno de los horizontes se encuentra en la autoeducación individuo como sujeto involucrado en el proceso de estudio y el aprendizaje en la búsqueda constante de conocimiento.

PALAVRAS CLAVE: La educación. La humanización. La universidad pública.

\footnotetext{
${ }^{1}$ Professora doutora da Universidade Federal do Tocantins e do Programa de Pós-Graduação em Letras e no Programa de Pós-graduação em Educação. Membro da Rede Internacional de Escolas Criativas - RIEC. Email: mjpgon@mail.uft.edu.br

2 É graduado em Pedagogia Plena pela Universidade Federal do Tocantins (2014). Especialista em Culturas e História dos povos Indígenas (2016) pela Universidade Federal do Tocantins (UFT). Graduando em Letras: Inglês-Espanhol pela AEDUC (Associação Especialista em Educação) (2017). Atualmente é professor de Língua Estrangeira Moderna-Inglês na instituição: U.E: Escola Estadual Girassol de Tempo Integral Manoel Messias (2017). E- mail: johndavid@ mail.uft.edu.br
}

RIAEE - Revista Ibero-Americana de Estudos em Educação, v.12, n.1, p. 496-506, 2017. $\quad$ E-ISSN: 1982-5587 
ABSTRACT: This article Aims to analyze education and its humanizing role in public university in Brazil, as well as their political act, in which there are different projects in dispute in society that reveal the various mechanisms and elements that make up thinking and doing in teaching in education higher. This is a theoretical research of bibliographic nature. The readings and the paths taken to analyze the object of research, had enormous contribution in the seminars and discussions during the class on the master discipline. We think this issue is relevant for think about the different projects to the public university, which can contribute to promoting the humanization or to reproduce the mechanisms of social domination. The study revealed that the challenge of public university in Brazil is to understand the social contradiction, economic and politics in the university. And one of the horizons it is in individual self-formation as a subject involved in the process of study and learning in the constant quest for knowledge.

KEYWORDS: Education. Humanization. Public university.

\section{Introdução}

A Educação está para além da Universidade. Limitá-la a educação universitária é perder o alicerce da formação humana, é transferir todo o conhecimento ontológico do ser para uma única instituição: universidade. Para além disso, os alicerces foram desde os primórdios a base da formação humana, como a: família, comunidade, religião, escola, universidade e mais tarde os partidos políticos.

Universidade pública deve ser vista como lócus que produz conhecimentos relevantes para a sociedade, assim como práticas políticas que esclarecem. Nela congrega discussões de conteúdos políticos que podem contribuir para manter e/ou transformar a sociedade. Manter, ao reproduzir discursos mercadológicos de transmissão do conhecimento para fins de empreendedorismo e transformar ao buscar a formação do trabalho humano assentado no pressuposto da humnazinação dos sujeitos.

O sentido primordial da Universidade é humanizar os sujeitos. E em concomitância a esse processo ensiná-los a técnica, as artes, as letras, a ciência, a filosofia, a lutar pelo bemcomum.

Estas questões devem ser pensadas no cenário atual, no qual, se tem uma enorme rejeição pela profissão docente; assim como a valorização do trabalho docente como principal mote de promessas e discursos proferidos por representantes políticos; e também o uso contínuo das palavras valorização e educação, fazendo com que, quanto mais se fala em valorização dos educadores, menos se faz por eles, em um país como este, onde a maioria dos docentes, não tem direito a um plano de carreira que lhe assegurem suas progressões. 
A universidade como intuição tem que compreender a contradição social, econômica e política. É importante enfatizar que cada um dos grupos que compõem e até mesmo os que esperam uma excelente produção da universidade tem uma ótica de universidade.

\section{Educação como processo humanizador e político}

A partir da educação Grega, inicia-se que eles chamavam de arete, uma educação, um ideal a ser seguido, em busca da virtude do homem. Essa educação estava fundamentada no princípio de que: $\mathrm{O}$ homem deveria ser educado para aprender a viver na polis. Polis era o nome que os gregos denominavam às suas Cidades-Estados, na qual todos os homens viviam em uma plena coletividade, na qual todas as riquezas eram produzidas e dividias de forma coletiva. No centro de cada cidade existia sempre uma praça, ou um espaço aberto chamado ágora. O homem era educado para aprender a discutir na ágora os sentidos políticos da cidade, ou seja, o futuro político da polis.

A busca pela perfeição era uma das características da educação Grega, sendo que o nome que se dava a essa educação era Paidéia. Entretanto a paidéia é maior que a educação, pois ela trata da formação geral do homem. Ela assumiu um significado que não pode ser encerrado em um conceito abstrato. Para tentar aproximar-se de um conceito sobre a paidéia na contemporaneidade, pode-se resumi-la, mas não conceituá-la, na união de alguns conceitos modernos: civilização, cultura, educação, tradição e literatura (JAEGER, 2001).

Em sua visão Grega, Platão citado por (JAEGER, 2001, p.147, grifo do autor) define Paidéia como "[...] a essência de toda a verdadeira educação ou Paidéia, a qual é educação na arete que enche o homem do desejo e da ânsia de se tornar um cidadão perfeito, e o ensina a mandar e obedecer a mandar e obedecer, sobre o fundamento da justiça". O conhecimento em Platão é visto como o Bem, uma ascensão através da dialética, isto é, o amor ao buscar o saber através do diálogo.

A partir destas ideias entende-se que o ato de educar abarca o processo de ensino e de aprendizagem de códigos e saberes historicamente acumulados pela sociedade nas mais diversas áreas, mas, extrapola esse conceito à medida que está também implicada nesse processo uma dimensão política, econômica e cultural, assim em um processo de formação humana. 
O homem como sujeito histórico, isto é, como um ser-no-mundo, ao nascer, não nasce homem, surge como criatura que precisa de mediação para garantir seu desenvolvimento físico e intelectual, ou seja, surge como ser biológico e natural. E ao entrar em contato com a cultura, a educação e com a sociedade ele se torna um ser racional. Isso através de um processo ininterrupto que o condiciona viver sempre em formação.

Desde os primórdios da formação do homem, o papel de educar, isto é, formar o homem, era tradicionalmente da família, ou seja, a família tinha a incumbência de garantir a educação da criança, que se dava na convivência do dia-a-dia, influenciando assim seus primeiros contatos com a cultura. Logo após, o papel de educar foi também divido com a comunidade, [...] "pois constituíam um corpo educativo formado, principalmente pelos mais idosos, que preservavam os princípios a serem seguidos por todos os membros da vida comunitária” (RODRIGUES, 2001, p. 252/253).

Em seguida a religião, também desempenhou um poder educativo em relação a uma série de valores invocados pelas comunidades. Após a religião, se integram também a esse processo as instituições sociais, como o Estado e seus aparelhos, a justiça, os partidos políticos, as organizações da sociedade civil e, do ponto de vista dos conhecimentos e habilidades, as instituições educacionais, incluindo a universidade (RODRIGUES, 2001).

Com o capitalismo como sistema de produção e exploração essas instituições de formação estão cada vez mais perdendo sua participação efetiva no ato educativo; esse ato era justamente o que antecedia qualquer instrução formal. Rodrigues (2001), afirma que:

As famílias têm perdido sua hegemonia educativa, na medida em que desestruturam as relações tradicionais entre seus membros. E não estamos a nos referir apenas às famílias das classes pobres, mas de todas as chamadas unidades familiares. Os pais estão cada vez mais ausentes da vida dos filhos, desde os primeiros dias de suas vidas. Igualmente, a Igreja deixou de representar uma instituição unitária e hegemônica, capaz de dar direção moral às novas gerações. $\mathrm{E}$ as comunidades desapareceram nas formas novas de organização da vida coletiva nos tempos modernos. Cada vez mais as pessoas apenas vivem fisicamente próximas, sem qualquer unidade de projetos sociais, de princípios éticos, de trabalho, de dever, de relações. As cidades, por sua vez, se transformaram em simples aglomerações populacionais e não são formas de organização humanitária da vida coletiva ( p.253).

Com a supremacia do capitalismo e dos processos educativos bem como suas teorias no contexto hodierno ocorre que, todas essas bases de sustentação da formação: família, comunidade, religião, partidos políticos, escolas e até a universidade estão se desintegrando em meio à ideologia de mercado do capitalismo: o neoliberalismo. 
Isso porque o mercado não pode consolidar tradições, isto é, manter as estruturas já estabelecidas em ascensão em prol ao bem-comum da sociedade. Tudo o que produz “desmancha no ar” devido a sua operacionalização rápida de mais mercado, isto é, acelerada produção e consumo e, menos estado, pouquíssima intervenção e apenas regulamentação do estado na concorrência. No Brasil esse sistema destrutivo influenciou tanto o sistema econômico e como no sistema político educacional.

Com base da leitura do livro: Escritos sobre os sentidos da escola, o autor Ildêu Coelho (2012) enfatiza que no mundo globalizado o saber, os livros, os cursos e a formação são reduzidos a informações, a mercadorias, ou ao poder político através de disputa de interesses. Tudo se submete a lógica da competição e da troca.

A escola desconhece as contradições vividas entre os homens e a sociedade. Em nome da mudança nada muda. Ao assumir os interesses e o modo de operar do mundo dos negócios, a escola se transforma em um lugar que nega o ócio e se torna espaço de disputa de poder. Assim ela se empobrece culturalmente e se reduz a organização, isto é, em local que prepara tecnicamente para o trabalho (COÊLHO, 2012).

Segundo o autor cabe a escola retomar seu papel político e emancipador de iniciação lenta e persistente, crítica e rigorosa dos estudantes no mundo da reflexão, da ética, da tecnologia, das letras, da filosofia, das artes e da ciência.

Assim, o sentido da escola é formar homens que, em sua práxis, irão instituí-la e conservá-la, recriando-a ao longo do tempo e configurado o sentido e a importância fundamental da educação na vida dos sujeitos. A educação nessa perspectiva a educação é, então, o permanente movimento de passagem do homem como ser natural e biológico ao ser racional, autônomo e livre que cuida do bem comum, do que é de todos, realizando-se, assim como humano (COÊLHO, 2012).

\section{A função da universidade pública no Brasil atual}

Sabe-se que as primeiras universidades brasileiras foram criadas a partir de $1912 \mathrm{com}$ a criação da Universidade do Paraná; em 1920 com a criação da Universidade do Rio de Janeiro; em 1927 a Universidade de Minas Gerais. Estas eram as universidades existentes antes da edição do Decreto $\mathrm{n}^{\circ}$ 19.851, de abril de 1931 que instituiu o Estatuto das Universidades Brasileiras, como informa. (ROMANELLI, 1982, p. 132). 
$\mathrm{Na}$ compreensão desta autora a "primeira universidade a ser criada e organizada, segundo as normas do Estatuto das Universidades, foi a Universidade de São Paulo, em janeiro de 1934" (p. 132). E uma das primeiras instituições de ensino superior, com uma estrutura que apontava investimento na área de educação, mesmo com problemas:

Foi a criação da Universidade do Distrito Federal, em 1935 por Anísio Teixeira, como Secretário de Educação, com uma estrutura arrojada, pelo fato de não possuir as três faculdades tradicionais e ter uma Faculdade de Educação, na qual se situava o Instituto de Educação. Em 1939 esta Universidade foi extinta e incorporou-se à Universidade do Brasil, na qual se transformara a Universidade do Rio de Janeiro, desde 1937. (ROMANELLI, 1982, p. 133).

A criação das universidades contribuiu com o fortalecimento dos debates visando mudanças na educação para que esta se adequasse às exigências da sociedade urbanizada e em franco processo de industrialização. Por outro lado, ficou evidente que a educação foi um dos instrumentos da luta política ideológica de diferentes grupos políticos e sociais que procuravam influenciar a vida nacional.

Com imersão das universidades no mundo do trabalho, ou melhor, no mundo capitalista, fez com que rapidamente surgissem críticas contra seu próprio modo de formar os sujeitos. Nesse contexto de transformações sociopolíticas, a universidade como instituição formadora, luta também para não submergir no mundo da competitividade e da neutralidade.

Desde seu surgimento no século XIII na Europa, a universidade sempre foi uma instituição social, isto é, com autonomia para a intervenção e ação na sociedade. $\mathrm{Na}$ modernidade a universidade fundamenta-se na premissa da autonomia do saber e face ao poder da religião e do Estado. Segundo Chaui (2003):

É exatamente por ser uma instituição social diferenciada e definida por sua autonomia intelectual que universidade pode relacionar-se como o todo da sociedade e com o Estado de maneira conflituosa, dividindo-se inteiramente entre os que são favoráveis e os que são contrários à maneira como a sociedade de classes e o Estado reforçam [...] (p.6).

As reformas educativas tiveram por finalidade adequar a universidade às expectativas e necessidades da nova ordem econômica, política e tecnológica. O eco das transformações do sistema econômico, político e social determinam as exigências a educação, e para atender essas demandas é necessário que se pense nas urgências de mudanças e reformulações do campo educativo, principalmente no que diz respeito a universidade. 
Estas exigências e perspectivas conduzem a novos significados a universidade. Um deles como de organização um "[...] conjunto de meios (administrativos) particulares para obtenção de um objetivo particular [...]. A sociedade aparece como uma rede móvel, instável, efêmera de organizações particulares redefinidas[...]” (CHAUI, 2003 p.7).

Esta perspectiva de universidade é pensada a partir da ideia de administração, que é inseparável do modo de produção capitalista, que por consequência ao mercado, transformando a universidade em uma organização social, isto é, numa prática administrativa. Esta prática instrumental não objetiva analisar seu sentido na sociedade não questiona sua função na formação de indivíduos.

Segundo Mello; Filho; Ribeiro (2004) destaca três desafios para uma universidade relevante. O primeiro desafio que a universidade brasileira enfrenta basicamente é: Atingir o padrão de qualidade. Assim significa dizer que todo o sistema deve ser compatível com as exigências: Do mundo contemporâneo; O estado de evolução; Dinamização do conhecimento em todos os domínios de manifestação e por último incorporar os avanços pedagógicos compatíveis.

O segundo é referente ao direito de acesso à universidade pública as populações de baixa renda, mesmo que não seja para todos os cidadãos que têm o direito a uma educação plena, mas que sirva a todos que: demonstrarem vocação; aptidão e motivação. Para formar-se nos níveis superiores de educação.

E por último segundo Mello; Filho; Ribeiro (2004) desenvolver o comprometimento orgânico de suas estruturas acadêmicas, ou seja, que os programas desenvolvidos sejam socialmente relevantes e que sejam também capazes de: contribuir com a solução de problemas nacionais inadiáveis e superar as distintas modalidades de exclusão ou carência socialmente estrutural.

Com a fragilidade da sociedade civil em âmbito nacional, a função da universidade para os autores gira em torno de uma universidade que deve ser: Culturalmente engajada; comprometida com os problemas da sociedade; Superação da pobreza crônica; Fim do analfabetismo e a geração de alternativas econômicas (MELLO; FILHO; RIBEIRO, 2004).

A função da universidade está na:

Relevância social, em outros termos, significa igualmente não abdicar, a instituição universitária, de sua função pública primordial de espaço de preservação e renovação dos valores democráticos e republicanos; de arena do pensamento crítico e inquieto; de centro da vida intelectual que sustenta uma relação reflexiva e ativa com o mundo circundante (MELLO; FILHO; RIBEIRO, 2004, p. 2) 
Corroborando com a ideia dos autores, Chaui (2003) defende a ideia de instituição, ou seja, o reconhecimento da sociedade. Tem a sociedade tem seu princípio e referência em suas pesquisas e formação política do indivíduo. Isto é, a instituição "[...] tem a sociedade como seu princípio e sua referência normativa e valorativa, enquanto a organização tem apenas a si mesma como referência, num processo de competição com outras que fixaram os mesmos objetivos particulares" (p.7).

Segundo Mello; Filho; Ribeiro (2004, pp. 2-3) destacam que:

A Universidade, por não ser empresa, rejeita o papel de máquina de produtividade econômica e de competitividade. Não pode se engarrafar nas ruas do mercado. Pois nada substitui seu potencial crítico; sua autonomia de pensamento; sua capacidade de pronunciamento, em tom argumentativo, para a comunidade mais ampla; seu poder de disseminação da reflexividade; sua vocação por excelência de centro de criação, questionamento e crítica do mundo físico e social (e de si mesma). Nesse sentido, o conhecimento acumulado em seus ciclos de estudos, em seus laboratórios e grupos de pesquisa, por meio de programas de extensão e outras ações abertas à sociedade, também precisa tornar-se patrimônio de todos, à disposição das comunidades e grupos locais, sobretudo das camadas sociais mais pobres, as quais, de outra forma, jamais teriam acesso a tais recursos.

Compreende-se que há desafios na formação universitária, principalmente em meio as mudanças paradigmáticas da sociedade, isso exige continuidade na sua formação para que se possa chegar ao nível de criticar as exigências e insatisfações que o sistema econômico, político e social faz para na universidade.

A universidade como intuição tem que compreender a contradição social, econômica e política. É importante enfatizar que cada um dos grupos que compõem e até mesmo os que esperam uma excelente produção da universidade tem uma ótica de universidade.

O que se observa no cenário hodierno nas instituições de ensino superior é que há de certa forma uma grande dificuldade em articular o saber produzido aos interesses sociais, que acabam refletindo na formação de professores tornando-os sujeitos individualistas e competitivos. Parece até que estamos reproduzindo a divisão social do trabalho e incitando a lógica de mercado, ou até mesmo, não formando nem para a autonomia nem para o capital, mas para um comodismo alienante que por mais paradoxal que pareça beneficia o capital.

Segundo Chaui (2000, p.1):

As grandes empresas se queixam da formação universitária que não habilita os jovens universitários ao desempenho imediatamente satisfatório de suas 
funções, precisando receber instrução suplementar para exercê-las a contento. A classe média queixa-se do pouco prestígio dos diplomas e de carreiras que lançam os jovens diplomados ao desemprego e à competição desbragada. Os trabalhadores manuais e dos escritórios, bancos e comércio queixam-se do elitismo das universidades, que jamais se abrem o suficiente para recebê-los e formá-los, mantendo-os excluídos das esferas mais altas do conhecimento e das oportunidades de melhoria de condição de vida e trabalho. Os estudantes se queixam da inutilidade dos cursos, da rotina imbecilizadora, das incertezas do mercado de trabalho, da pouca relação entre a universidade e os problemas mais prementes da sociedade. Os professores estão insatisfeitos com as condições de trabalho, de salário, de ensino e pesquisa, com a estupidez das máquinas burocráticas que cretinizam as atividades universitárias, submetendo-as a rituais desprovidos de sentido e de fundamento, com o autoritarismo das direções, a heteronomia dos currículos e as lutas mesquinhas pelo poder e pelo prestígio.

Esse paradoxo da universidade se dá pelo distanciamento de sua função primordial, que é humanizar os sujeitos. E em concomitância a esse processo ensiná-los a técnica, as artes, as letras, a ciência, a filosofia, a lutar pelo bem-comum. A universidade tem por função compreender a contradição social, econômica e política. É importante enfatizar que cada um dos grupos que compõem e até mesmo os que esperam uma excelente produção da universidade tem uma ótica de universidade.

Portanto, compreende-se que é possível que haja diferentes projetos para a universidade pública em disputa na sociedade e que eles revelam-se nos diversos mecanismos e elementos que compõem o pensar e o fazer na universidade e nas dimensões educativas na sociedade.

\section{Considerações finais}

A universidade como instituição pública tem que compreender a contradição social, econômica e política. É importante enfatizar que cada um dos grupos que a compõem, esperam uma excelente produção da universidade para sociedade

É necessário como ponto de partida entender que a educação universitária é um ato político. Ou seja, atua como uma instituição que tem autonomia para criticar a sociedade, e que pode contribuir para subverter a lógica de dominação e exploração humana, por meio de uma ação transformadora de nossas práticas sociais, objetivando a formação humanizadora do sujeito.

Em outras palavras a formação universitária pode contribuir para promover a humanização quando nos preparam para assumir a nossa autonomia como cidadão e 
trabalhador. E também pode servir também aos interesses de quem busca privilégios mercadológicos e políticos.

Sua função está em uma perspectiva humanizadora que esclarece e não que aliena. Isso quer dizer que, ela congrega conteúdos políticos que pode contribui para manter e/ou mudar a sociedade de dominação, ao buscar a formação do trabalho humano assentado no pressuposto para emancipação dos sujeitos.

Portanto, compreende-se que é possível que haja diferentes projetos para a universidade pública em disputa na sociedade e que eles revelam-se nos diversos mecanismos e elementos que compõem o pensar e o fazer na universidade e nas dimensões educativas na sociedade.

Um dos horizontes está na autoformação do indivíduo enquanto sujeito envolvido no processo de estudo e aprendizagem. $\mathrm{Na}$ busca incessante pelo conhecimento que não se encontra apenas nos professores, mas principalmente nos livros (clássicos), na produção de um mundo de: leitura, estudo, escrita, crítica, direito e principalmente de humanidade.

\section{Referências}

CHAUI, M. A Universidade pública sob nova perspectiva. Revista. Bras. Educ. 2003, nº 24, pp. 515.

CHAUI, M. Produtividade e humanidades. Revista Tempo Social. 2000, v. 2, n. 3, p. 4571.

COÊLHO, I. M. Escritos sobre o sentido da escola. In: COÊLHO, I. M.(Org.). Escritos sobre o sentido da escola: uma introdução. Campinas, SP: Mercado de letras, 2012.

JAEGER, W. Paidéia: A formação do homem grego. Lisboa: Editorial Aster, 1981

MELlO, A. F.; FILHO. N. A.; RIBEIRO.R. J. Por uma universidade socialmente relevante. 2004.

RODRIGUES, N. Educação: da formação humana à construção do sujeito ético. Educação \& Sociedade, ano XXII, $\mathrm{n}^{\mathrm{o}}$ 76, Outubro/2001, p. 232. Disponível em: <http://www.scielo.br/pdf/es/v22n76/a13v2276.pdf>. Acesso: 12 out. 2013.

ROMANELLI, O. de O. História da Educação no Brasil. 3. ed. Vozes: Petrópolis, 1982. 


\section{Como referenciar este artigo}

PINHO, Maria José de; SANTOS, John David Ribeiro. Educação como processo humanizador e político na universidade pública. Revista Ibero-Americana de Estudos em Educação, Araraquara, v.12, n.1, p. 496-506, 2017. Disponível em: <http://dx.doi.org/10.21723/riaee.v12.n1.8201>. E-ISSN: 1982-5587.

Data de submissão: nov/2015

Aprovação final: dez/2016 